\title{
Performance Assessment of RC Framed Buildings with Shear Wall Due to Effect of Soil Flexibility
}

\author{
Ajay Kumbar and Dr.S.B. Vanakudre
}

\begin{abstract}
During Earthquake the structural behavior varies not only by the response of superstructure but also with the response of soil beneath. In the past, conventional analysis is carried out taking the fixed base. The structure is analyzed using software called SAP2000.IS 1893-2002 design code is used for soil structure system. To resist large horizontal loads, shear walls are used. The geometrical configuration of these shear walls alters the response of the structure. In the present study, RC framed building of 4, 6, 8 and 12 storeys with various locations of shear walls resting on different types of soils subjected to seismic loading. The type of soil is based on the values of Shear modulus and Poisson's ratio. In this paper as the difference in soil with varying storey height and shear wall, the variation of natural period and base shear is observed. Study shows that the natural period is giving lower value in Shear wall 02.This study also shows the value of Base shear is highest in the case of without shear wall which is rested on soft soil.
\end{abstract}

Keywords--- Soil Structure Interaction, Shear Wall, Natural Period, Base Shear, SAP2000

\section{INTRODUCTION}

$\mathrm{N}$ ORMALLY the standard structural analysis of RC Space Frame is done accepting base of building frame is to be fixed and by disregarding the effect of Soil Flexibility. Be that as it may practically speaking the building frames dependably lay on deformable soil bringing about redistribution of forces and moments because of SSI effect, caused not just by the response of the superstructure, but Likewise by the response of the subsoil underneath. Therefore conventional analysis is unrealistic and may be unsafe in many cases. Usually the properties of soil, structure and nature of excitation are dependable on the effect of soil on response of structures. Fixed base analysis disregarding the effect of soil flexibility are for the most part done for the seismic design of building of structures which results in either potentially excessive or unsafe design. In order to design earthquake resistant structures correctly, the interaction between structures and soil needs to be modeled accurately.

Seismic soil structure interaction is an important part in the comprehending of disappointment of the structures yet then it is exceptionally complex to analyze. The process, in which the response of the soil influences the motion of the structure and vice versa, is referred to as Soil-Structure Interaction (SSI).

Ajay Kumbar, PG Student, Dept of Civil Engineering, SDMCET, Dharwad, India.E-mail:a.m.kumbar@gmail.com

Dr.S.B. Vanakudre, Principal, Dept of Civil Engineering, SDMCET, Dharwad, India.E-mail:shrikantvanakudre@gmail.com DOI:10.9756/BIJMMI.8175
Soil structure interaction analysis is an exceptional field of earthquake engineering. Common sense lets us know that each seismic structural response is brought about by soil structure interaction forces affecting structures. However engineering community used to discuss about soil structure interaction just when these interaction forces can change the basement motion as compared to the free field ground motion. So, historically the standard definition of SSI is not the same as basic event of communication forces. These forces happen for every structures but not generally they can change the soil motion.

Jayalekshmi B.R and Chinmayi H.K [1] studied the effectiveness of shear wall locations on RC frame buildings of varying height with raft foundation by noting the effect of soil flexibility on change in lateral natural period. Kalyanshetti M.G.[2]showed that the multi-storey reinforced concrete framed buildings of different heights with shear wall at five alternate locations in the building is considered to investigate the effectiveness of shear walls to control SSI. The study is carried out using Winklerian approach. Shear walls play important role very effective when placed centrally, near tocentroid of building in resisting seismic load. Ayman Ismail[3] paper discusses the importance of considering the effect of soil stiffness on the seismic performance of rigid structural frame system resting on it observed that modulus of soil has considerable effect on natural period of system and overall performance of structural system, indicating that idealization of fixity at the base may be seriously erroneous.

In Present study, a comparison is made between building frames resting on fixed base and flexible condition. Further discussion is by considering a flexible base condition with shear wall at various location to evaluate to control the SSI effect. The building is carried out in different stages: Flexible base condition, Fixed base condition, Flexible base with shear wall, and Fixed base with shear wall. The effectiveness of shear wall locations to identify the most beneficial location to control SSI effect.

\section{IDEALIZATION OF THE SYSTEM}

\section{A. Structural Idealization}

To inspect the dynamic conduct while considering the impact of soil-structure interaction, building frames of 4,6 , 8,12 story with and without shear wall was admired as 3D space outlines utilizing three longitudinal degrees of freedom and three rotational degrees of freedom at every node. In the present analysis the symmetric 5 x 5 bay reinforced concrete building frames of 4,6,8,12 storeys are considered. Structures constitute conventional moment resisting frames of 5 bays of equivalent length of $3 \mathrm{~m}$ in each direction and story height is considered as $3 \mathrm{~m}$. The thickness of Shear walls that are 
considered at various locations in the plan are varying from $0.15 \mathrm{~m}$ to $0.2 \mathrm{~m}$. The Slab thickness of $0.15 \mathrm{~m}$ is considered for all storeys. On the basis of structural design in accordance with IS 456:2000 Building component dimensions are evaluated considering M25 concrete and Fe 415 steel. The details of building frames are given in Table 1.The dimensions of beam taken is $0.23 \times 0.23 \mathrm{~m}$ up to 8 storey and above 8 storey $0.3 \times 0.3 \mathrm{~m}$ is considered.

Table 1: Dimensions of Components of Building

\begin{tabular}{|l|l|l|l|l|}
\hline Storey & Column $(m \times m)$ & Beam $(m \times m)$ & Shear wall $(m)$ & Slab $(m)$ \\
\hline 4 & $0.3 \times 0.3$ & $0.23 \times 0.23$ & 0.15 & 0.15 \\
\hline 6 & $0.35 \times 0.35$ & $0.23 \times 0.23$ & 0.15 & 0.15 \\
\hline 8 & $0.4 \times 0.4$ & $0.23 \times 0.23$ & 0.20 & 0.15 \\
\hline 12 & $0.5 \times 0.5$ & $0.3 \times 0.3$ & 0.20 & 0.15 \\
\hline
\end{tabular}

The idealized form of a typical 5 bay x 5 bay frame of equal length of $3 \mathrm{~m}$ in each direction with different shear wall locations in the building denoted as SW1 to SW4 and Bare frame $\mathrm{BF}$ are represented schematically which is shown below.

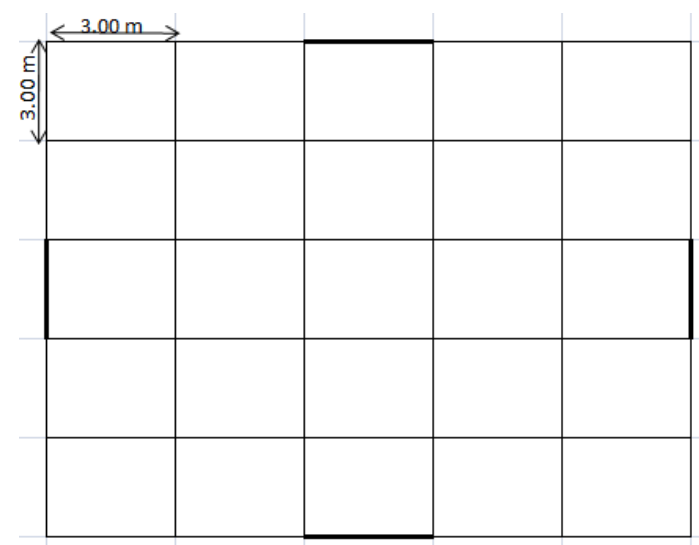

SW1

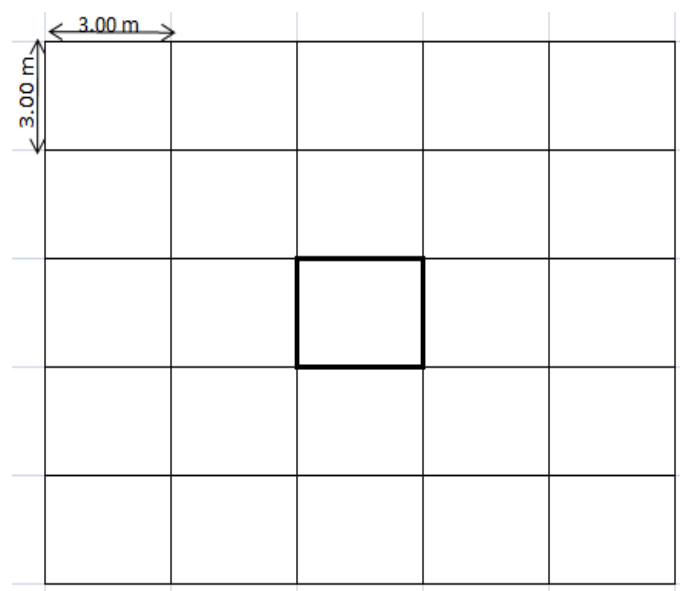

SW2

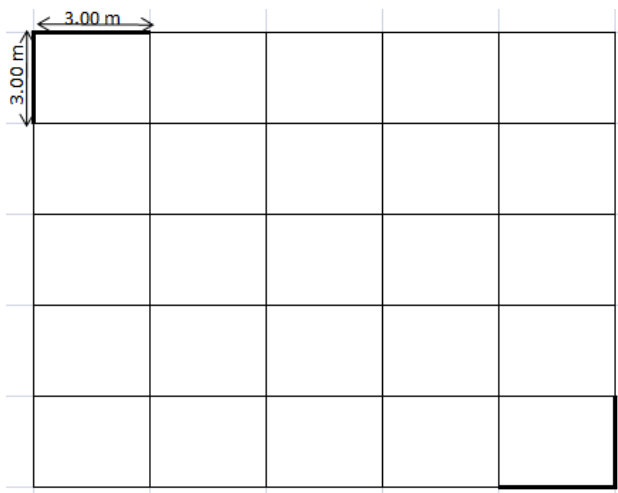

SW3

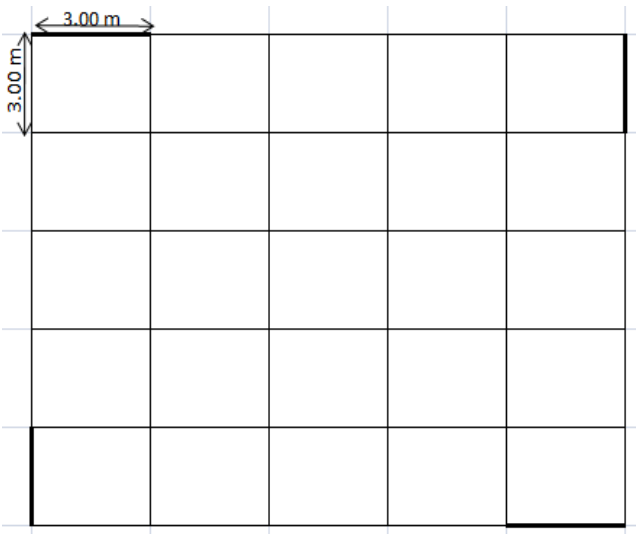

SW4

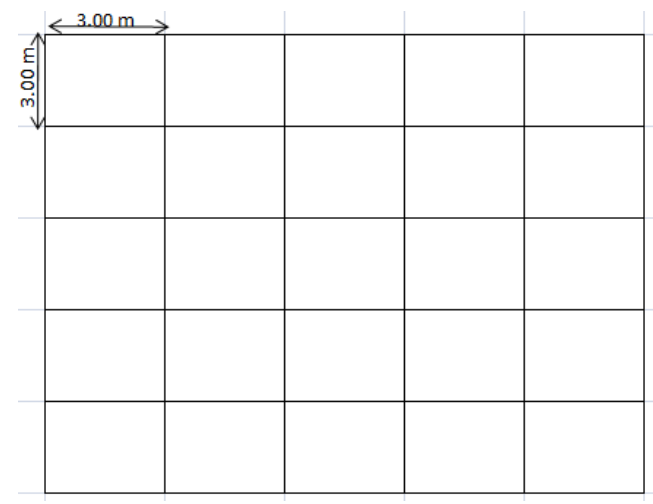

$\mathrm{BF}$

Various Locations of Shear Wall in the Building Frame and Bare frame

Buildings frames without shear wall are denoted as "BF" and frames with shear wall at different locations as "SW1, SW2, SW3 and SW4".

\section{B. Soil Idealization}

Soil is treated as an Isotropic, Homogenous and Elastic half space medium to analyze the Soil and Structure. The Inputs for analysis are Shear modulus $(\mathrm{G})$ and Poisson's ratio $(\mu)$. The effect of Soil-structure interaction on buildings resting on different types of non-cohesive soil, viz., stiff, medium andsoft. The details of different soil parameters are as tabulated in Table 2. 
Table 2: Details of Soil Parameters Considered

\begin{tabular}{|l|l|l|l|}
\hline Soil profile type & Description & $\begin{array}{l}\text { Shear modulus }(G) \\
\left(K N / m^{\wedge} 2\right)\end{array}$ & Poission's ratio \\
\hline Type 1 & Stiff Soil & 30000 & 0.2 \\
\hline Type 2 & Medium Soil & 20000 & 0.25 \\
\hline Type 3 & Soft Soil & 10000 & 0.3 \\
\hline
\end{tabular}

\section{METHODOLOGY}

The Analysis of Building frames is carried out using Software SAP2000 in accordance with IS: 1893-2002 considering Z (Zone Factor) $=0.10$, I (Importance Factor) $=1$, $\mathrm{R}$ (Response Reduction Factor) $=5$.

In this software, identify the Variation between flexible and fixed base with and without shear wall. Also by changing the height of the storey, observe the effect in the following parameters: Natural time period, Base shear.

A Typical building frame with and without interaction using shear wall is shown in the fig.

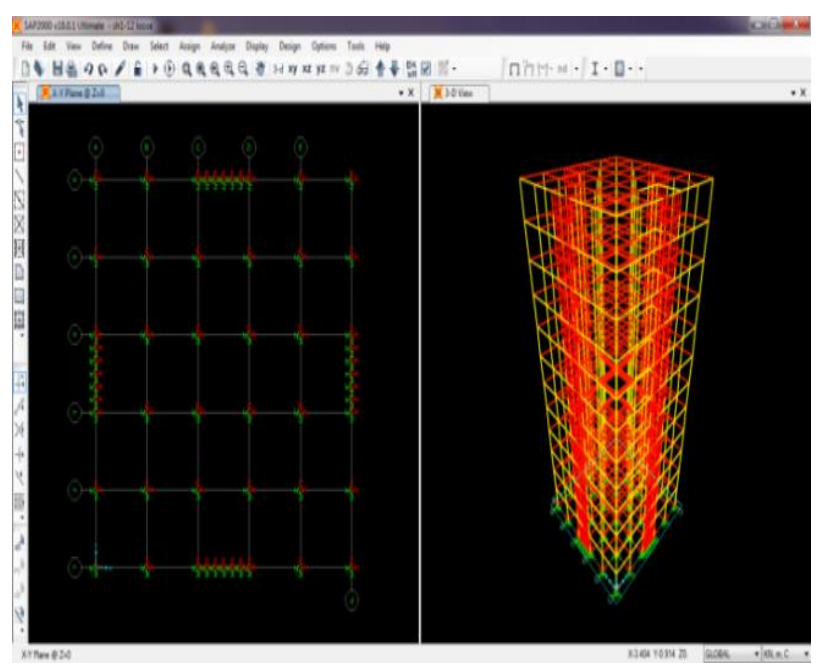

Figure 1: Plan and Elevation of 12 Storey Building with Shear Walls with Flexible Base Condition

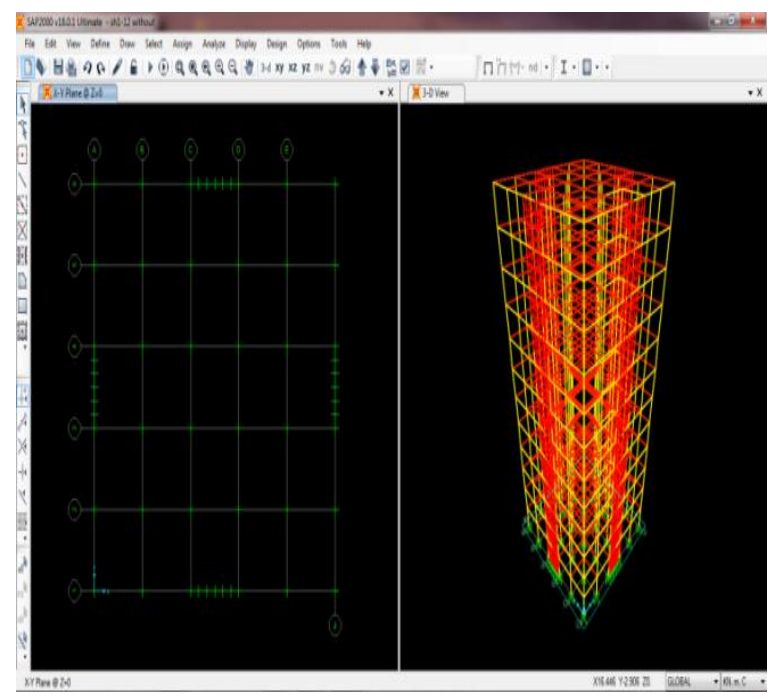

Figure 2: Plan and Elevation of 12 Storey Building with Shear Walls With Fixed Base Condition

\section{RESULTS AND DISCUSSIONS}

\section{A. On lateral Natural Period}

The modification in fundamental lateral natural period due to the effect of soil-structure interaction was studied on a building of 4,6,8 and 12 story on various soil types viz. Stiff, Medium and Soft soil. The percentage variation in lateral natural period with and without shear walls incorporating Soil Stiffness is as tabulated in the table shown below.

Table 3: Variation in Lateral Natural Period

\begin{tabular}{|l|l|l|l|l|}
\hline \multirow{2}{*}{ Description } & \multicolumn{3}{|l|}{ With interaction } & \multirow{2}{*}{ Without interaction } \\
\cline { 2 - 5 } & Soft & Medium & Hard & \\
\hline Bare Frame & 0.684 & 0.624 & 0.609 & 0.517 \\
\hline Shear wall-1 & 0.586 & 0.480 & 0.459 & 0.266 \\
\hline Shear wall-2 & 0.538 & 0.473 & 0.445 & 0.270 \\
\hline Shear wall-3 & 0.581 & 0.5319 & 0.511 & 0.350 \\
\hline Shear wall-4 & 0.619 & 0.560 & 0.537 & 0.359 \\
\hline
\end{tabular}

Below shows the graph of Lateral natural period with soil. Shear modulus values are nothing but type of soils.(Soft soil10 ,Medium-20, stiff-30).

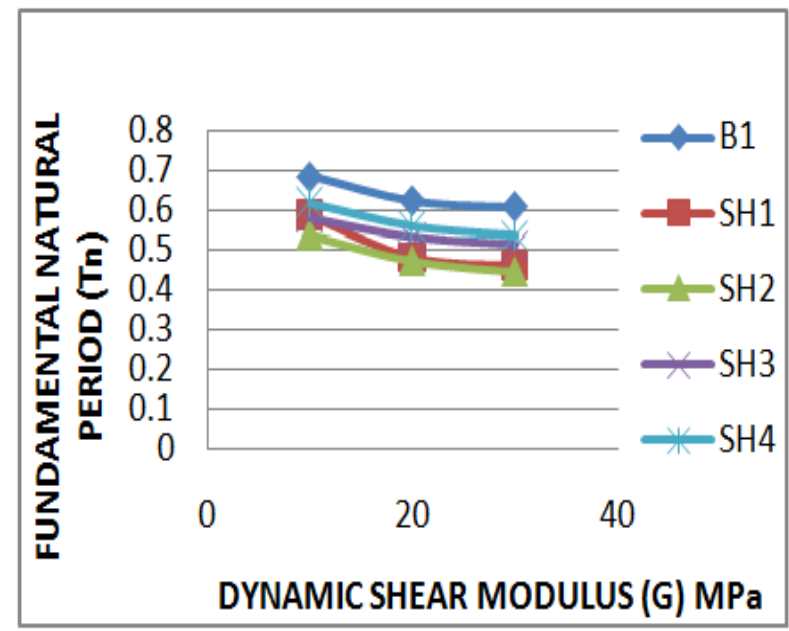

Figure 3: Variation of Lateral Natural Period in 4 Storey Building.SH1, SH2, SH3, and SH4 is Different Positions of Shear Wall

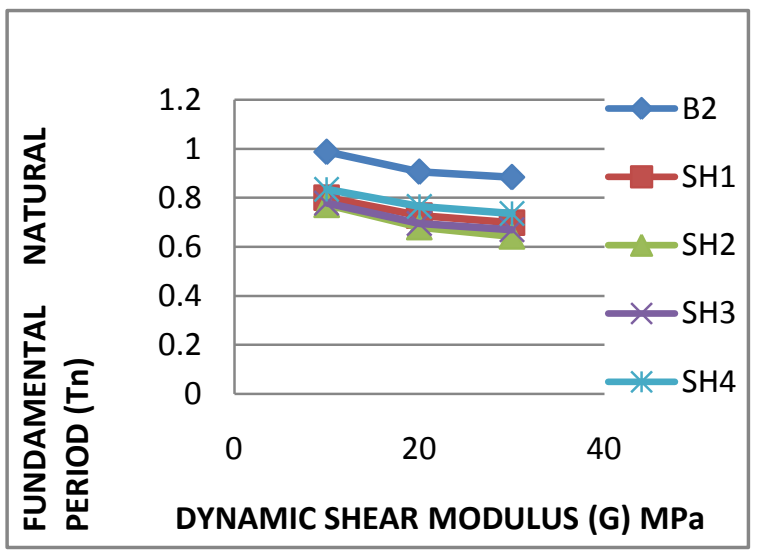

Figure 4: Variation of Lateral Natural Period in 6 Storey Building 


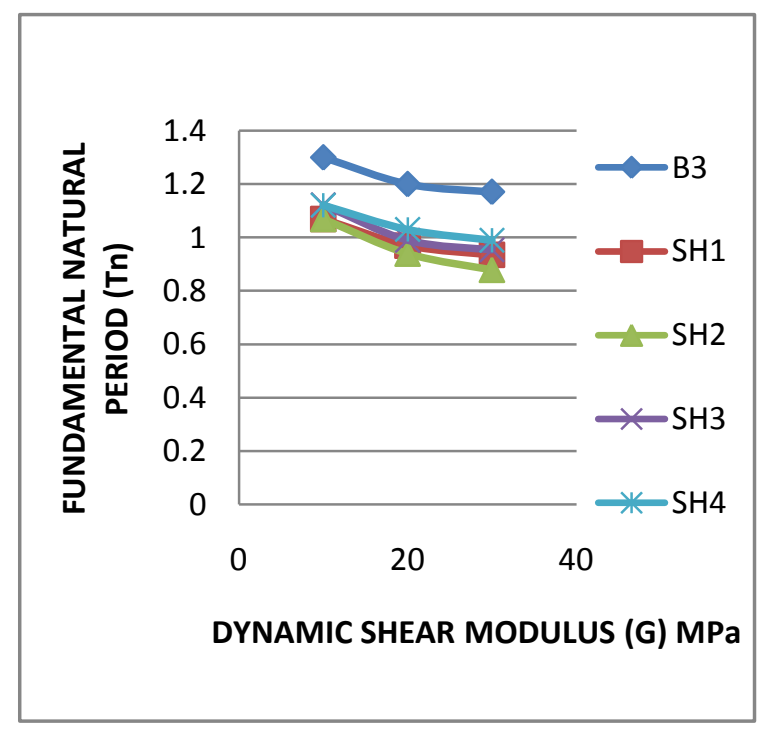

Figure 5: Variation of Lateral Natural Period in 8 Storey Building

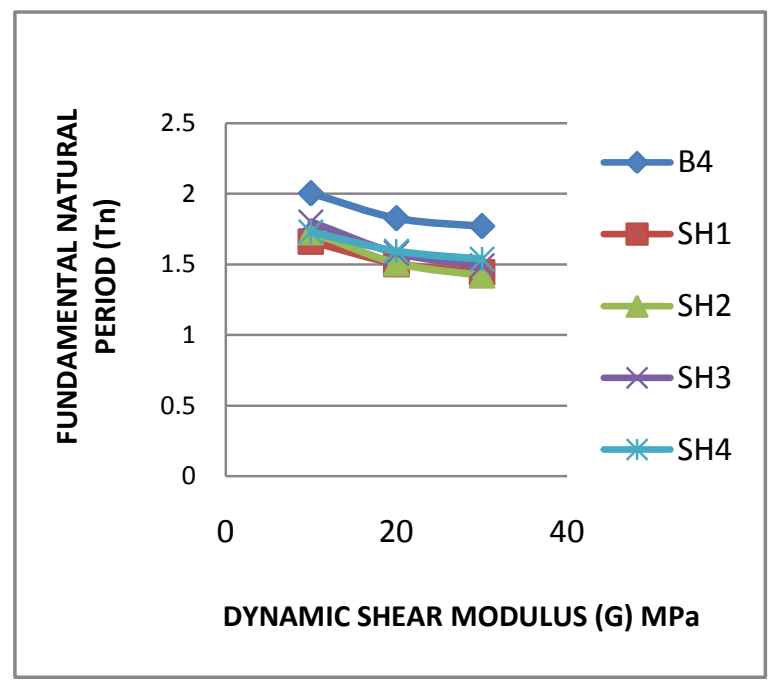

Figure 6: Variation of Lateral Natural Period in 12 Storey Building

\section{B. On Base Shear}

Present section presents the variation in base shear due to the effect of soil-structure interaction for building frames with and without shear wall and are presented in different storey shown in table below.

Table 4: Variation in Base shear

\begin{tabular}{|l|l|l|l|}
\hline \multirow{2}{*}{ Description } & \multicolumn{3}{|l|}{ With interaction } \\
\cline { 2 - 4 } & Soft & Medium & Hard \\
\hline Bare Frame & 9930.92 & 8246.89 & 7670.66 \\
\hline Shear wall-1 & 7964.74 & 8391.16 & 8302.9 \\
\hline Shear wall-2 & 7902.87 & 8028.14 & 7974.3 \\
\hline Shear wall-3 & 7755.78 & 7904.04 & 7923.70 \\
\hline Shear wall-4 & 8852.55 & 7657.31 & 7760.57 \\
\hline
\end{tabular}

Below shows the graph of Base shear with variation in soil. Shear modulus values are nothing but type of soils.(Soft soil-10 ,Medium-20, stiff-30).

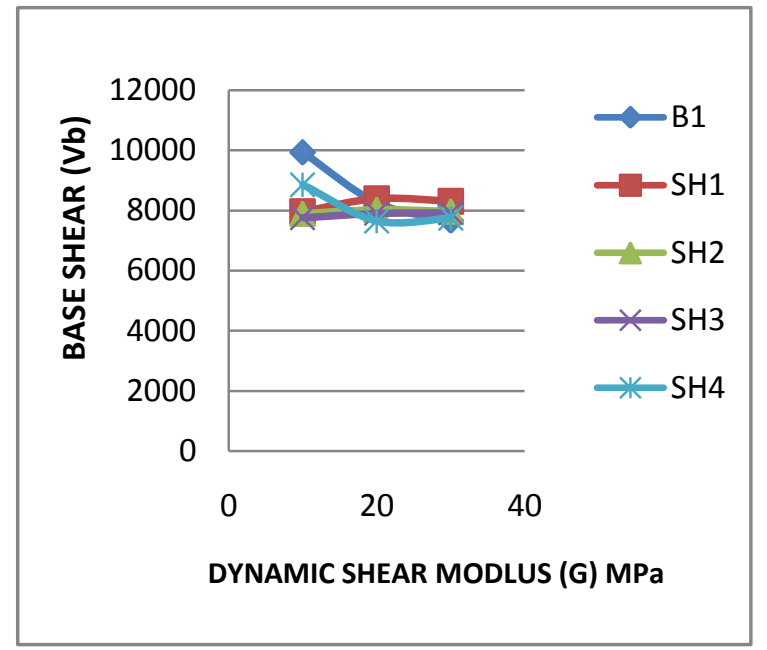

Figure 7: Variation of Base Shear in 4 Storey Building

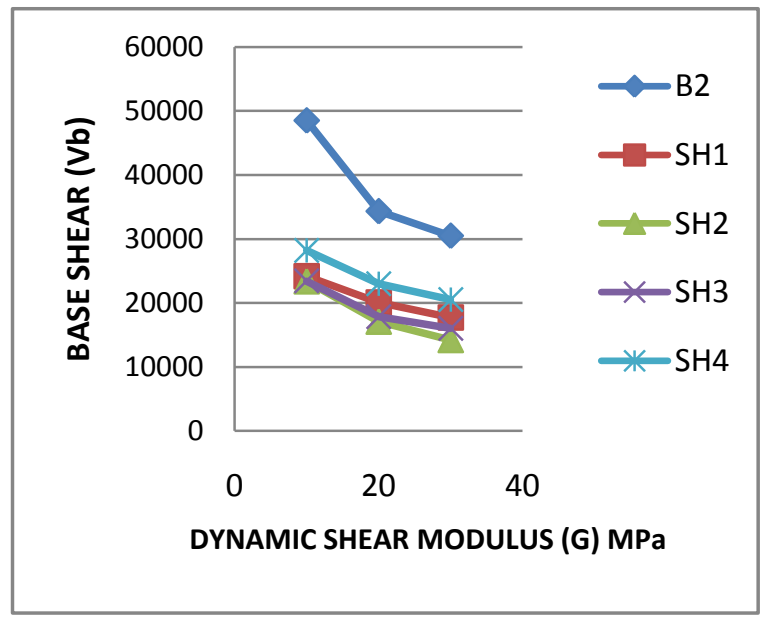

Figure 8: Variation of Base Shear in 6 Storey Building

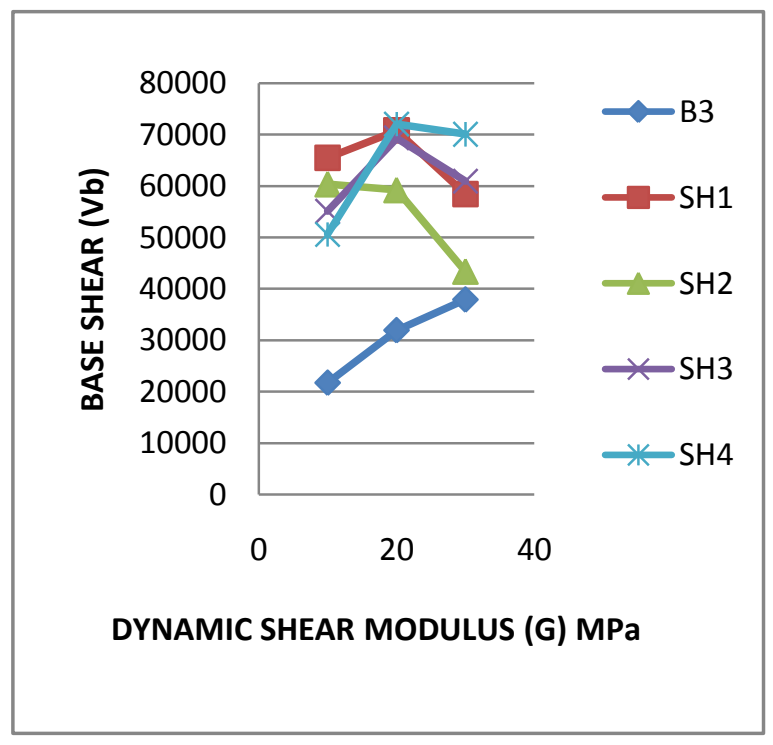

Figure 9: Variation of Base Shear in 8 Storey Building 


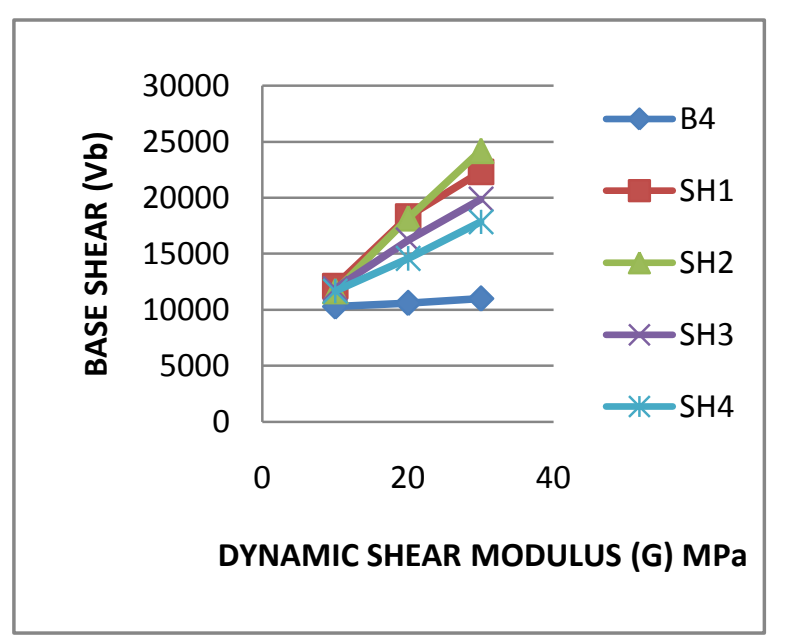

Figure 10: Variation of Lateral Natural Period in 8 Storey Building.

\section{CONCLUSION}

In the present study the reinforced symmetric building is analyzed for different storey and positioning of shear walls at different locations by including and not including soil structure interaction.

The results lead to following conclusions:

1) The natural period of the structure is usually Longer when it is analyzed as flexible base systems. It is also increases with soft soil i.e., with flexibility and increase in storeys.

2) Due to soil flexibility lateral displacement is increases as compared to fixed base.

3) Fundamental natural period of shear walls placed at four corners is more compared to that when shear wall placed at the center along with corners.

4) By providing shear walls in proper position, effects and damages due to earthquake and winds can be minimized. The results reveal that, the case SW2 have advantageous position of shear walls i.e. the shear wall placed centrally, near to centroid of building shows effective resistance to seismic load.

5) Base shear is minimum in the stiff soil as compared to medium and soft soil with second shear wall position (SW2).

6) Base shear is maximum where the shear wall is not provided (Bare frame) and soil is soft.

\section{REFERENCES}

[1] B.R. Jayalekshmi and H.K. Chinmayi, "Effect of Soil Flexibility on Lateral natural period in RC Framed Buildings with Shear Wall", International Journal of Innovative Research in Science, Engineering and Technology,Vol. 2, No. 6, 2013.

[2] M.G. Kalyanshetti, S.A Halkude, and R.N. Tambake, "Effect of Shear Wall in the Seismic Analysis of Building Frames Considering Soil Structure Interaction-A Study by Winklerian Approach", International Journal of Current Engineering and Technology, Vol 5, No. 5, 2015.

[3] A. Ismail, "Effect of Soil Flexibility on Seismic Performance of 3-D Frames", IOSR Journal of Mechanical and Civil Engineering, Vol. 11, No. 4, 2014.
[4] S. Hosamani, R.J. Fernandes, "Soil Structure Interaction of RC Framed Irregular Building with Shear Walls", International Research Journal of Engineering and Technology, Vol. 2, No. 4, 2015.

[5] Y. Lu, I. Hajirasouliha and A.M. Marshall, "Performance-based seismic design of flexible-base multi-storey buildings considering soil-structure interaction”, Engineering Structures, Vol. 108, Pp. 90-103, 2016.

[6] FEMA 356/November 2000, Prestandard and Commentary for the Seismic Rehabilitation of Buildings.

[7] J.E. Bowles, "Foundation Analysis and Design", 1996.

[8] IS 456: 2000, Criteria for Plain and Reinforced Concrete- Code of Practice (fourth revision).

[9] IS 1893 (Part I): 2002, Criteria for Earthquake Resistant Design of Structures-General provisions and Buildings. 